\title{
Comparative proteomics reveals molecular correlates of population-level variation in reproductive timing in a North American songbird
}

\author{
Devraj Singh ${ }^{1}$, Adam Fudickar ${ }^{2}$, Tara Smiley $^{1}$, and Ellen Ketterson ${ }^{1}$ \\ ${ }^{1}$ Indiana University Bloomington \\ ${ }^{2}$ Max-Planck-Institut fur Ornithologie
}

September 11, 2020

\begin{abstract}
Individuals and populations time annual events such as migration and reproduction to match favorable times in their environment. Physiological preparations for reproduction rely on predictive cues such as day length to accurately time reproduction. In birds, preparation typically begins with light reception by the hypothalamus, which initiates multiple central and peripheral responses. We studied two closely related populations of a songbird, the dark-eyed junco, that live in a common winter environment but diverge in their timing of reproduction as spring approaches. One population is resident and initiates reproduction earlier than the other, which migrates northward prior to reproducing. We caught resident and migrant juncos from the field during early spring and collected hypothalamic and pituitary tissues. We used isobaric tandem mass tag (TMT) labeling to identify differentially expressed proteins (DEPs) as possible regulators of the seasonal divergence in reproductive timing. We found 3038 unique proteins expressed in the hypothalamus and pituitary proteome, among which we identified 75 DEPs. These were associated with hormones, neurotransmitter secretion, transport, neuropeptide synthesis, prohormone synthesis, neurogenesis, GnRH synthesis, release and stability, food intake, locomotion, and social behavior. Some of these proteins were associated with early breeding in resident juncos, and others were associated with increased food intake, fat metabolism, locomotor activity and phenology in migratory juncos. Our results provide new insight into the neuroendocrine regulation of the timing of reproduction and migration. This study provides the first evidence of a relationship between functional protein variation in the neuroendocrine tissues and seasonal divergence in reproductive timing.
\end{abstract}

\begin{abstract}
Individuals and populations time annual events such as migration and reproduction to match favorable times in their environment. Physiological preparations for reproduction rely on predictive cues such as day length to accurately time reproduction. In birds, preparation typically begins with light reception by the hypothalamus, which initiates multiple central and peripheral responses. We studied two closely related populations of a songbird, the dark-eyed junco, that live in a common winter environment but diverge in their timing of reproduction as spring approaches. One population is resident and initiates reproduction earlier than the other, which migrates northward prior to reproducing. We caught resident and migrant juncos from the field during early spring and collected hypothalamic and pituitary tissues. We used isobaric tandem mass tag (TMT) labeling to identify differentially expressed proteins (DEPs) as possible regulators of the seasonal divergence in reproductive timing. We found 3038 unique proteins expressed in the hypothalamus and pituitary proteome, among which we identified 75 DEPs. These were associated with hormones, neurotransmitter secretion, transport, neuropeptide synthesis, prohormone synthesis, neurogenesis, GnRH synthesis, release and stability, food intake, locomotion, and social behavior. Some of these proteins were associated with early breeding in resident juncos, and others were associated with increased food intake, fat
\end{abstract}


metabolism, locomotor activity and phenology in migratory juncos. Our results provide new insight into the neuroendocrine regulation of the timing of reproduction and migration. This study provides the first evidence of a relationship between functional protein variation in the neuroendocrine tissues and seasonal divergence in reproductive timing.

\section{Introduction}

Each year as spring approaches and the climate warms in the north temperate zone, birds begin to breed or migrate northwards to their breeding grounds. This annual breeding or migration of birds reflects the seasonal recurrence of biological activities and is associated with the physiology of migration and reproduction. Previous research has shown that endogenous clocks are entrained by annual changes in day length (photoperiod), resulting in photo-induced phenotypes that correspond to seasonal life history states (LHSs; Helm et al., 2013). Each LHS is accompanied by characteristic changes in behavior, neural activity, physiology and hormones (Gwinner \& Helm, 2003; Trivedi, Kumar, Rani, \& Kumar, 2014). In species with a broad geographic range, closely related populations may differ in when they breed and whether they migrate. In some cases, populations co-occur geographically during winter, but because they differ in migration strategy, they also differ geographic distribution when breeding. In late winter early spring, the populations that do not migrate initiate reproductions while living side by side with the migratory populations that delay reproduction This system of differential response to the same environment thus provides a powerful model to investigate mechanistic differences at the neuroendocrine level associated with differences in the timing of reproduction.

The annual activation of seasonal reproduction is primarily regulated through the interaction of day length with the hypothalamic-pituitary-gonadal (HPG) axis (Cho, Hahn, MacDougall-Shackleton, \& Ball, 1998). Annual change in day length varies with latitude such that birds breeding at higher latitudes often require longer days to initiate gonadal recrudescence (Dawson, 2013; Fudickar et al., 2016a, Fudickar, Greives, Atwell, Strocker, \& Ketterson, 2016b; Singh et al., 2019). Photoperiodic responses depend on light perceived via encephalic photoreceptors falling during the stimulatory phase of a daily rhythm of sensitivity (Ball \& Balthazart, 2003; Follett, Kumar, \& Juss, 1992; Brandstätter, 2003; Yasuo, Watanabe, Okabayashi, Ebihara, \& Yoshimura, 2003; Nakane et al., 2010). The neuropeptides and hormones synthesized and released from the hypothalamic-pituitary (HP) complex are critical to the initiation of gonadal recrudescence. A vital step in the initiation of reproduction is the release of gonadotropin releasing hormone 1 (GnRH1), a key molecule released from the hypothalamus that binds to gonadotrophic cells located in the pituitary to stimulate release of the gonadotropins, luteinizing hormone (LH) and follicle-stimulating hormone (FSH) (Cho et al., 1998). Gonadotropins stimulate gonadal growth and the production and release of sex steroids. Synthesis of GnRH1 is regulated at the level of transcription, translation, and posttranslational modification to maintain the stability of active hormone. Hence investigating molecules involved in all of these different processes may provide explanations for differences in the reproductive timing of songbirds breeding at different latitudes.

Annual change in day length varies with latitude such that birds breeding at higher latitudes typically require longer days to initiate gonadal recrudescence (Dawson 2013; Fudickar et al., 2016b; Singh et al., 2019). However, birds that breed at higher latitude often migrate from wintering to breeding grounds and delay their reproduction despite increasing day length (Grieves, Fudickar, Atwell, Meddle, \& Ketterson, 2016; Fudickar et al., 2016b; Ramenofsky, Campion, Perez, Krause, \& Nemeth, 2017). Preparations for migration include a range of physiological changes such as increased food intake, fat deposition, increased metabolic activity in flight muscles and liver, and shifting from primarily diurnal behavior to a mix of diurnal and nocturnal activity (Piersma, Perez-Tris, Mouritsen, Bauchinger, \& Bairlein, 2005; Bairlein, 2003; Landys et al., 2005; Singh, Trivedi, Rani, \& Kumar, 2015; Singh, Swarup, Le, \& Kumar, 2018). The regulation of seasonally recurring reproduction and migration potentially involves the interaction of key molecules in the hypothalamus in a daily and annual phase-dependent manner that integrate signals for circadian and circannual time measurement and fine tune physiological and behavioral responses (Singh et al., 2015; Mishra, Bhardwaj, Malik, \& Kumar, 2017; Johnston, Paxton, Moore, Wayne, \& Smith, 2016).

The dark-eyed junco provides a powerful model system for investigating the neuroendocrine mechanisms 
that underlie variation in reproductive and migratory timing. In early spring populations of juncos that differ in when they reproduce and whether they migrate are found living together in the same environment. As spring progresses, locally breeding juncos undergo gonadal recrudescence, while migratory individuals that are sympatric during the non-breeding months delay recrudescence to prepare to migrate. In recent studies using this system, microarray and transcriptome sequencing techniques have revealed differential patterns of gene expression between residents and migrants in a limited number of tissues (Fudickar et al. 2016a; Johnston et al., 2016). However, a comprehensive account of the final products of gene expression through profiling of translated proteins is needed for a fuller understanding (Anderson, Matheson, \& Steiner, 2000) and can be provided by proteomics, including chains of amino acid sequences, post-translational modifications, characterization and identification of protein with relative or absolute quantification (Domon, \& Aebersold, 2010).

Here, we performed a global quantitative proteome analysis of the neuroendocrine tissue of seasonally diverged junco sub-populations that, while in sympatry, express striking differences in physiology and behavior in early spring. To identify differentially expressed hypothalamic and pituitary proteins associated with differences in seasonal timing of reproduction and migration, we first quantified global proteome abundance in neuroendocrine tissues using TMT labeling chemistry, LC-MS/MS, followed by characterization of specific proteins using junco open reading frame reference. Second, we identified differentially expressed proteins using the ShinyGO tool, an application based on large annotation and pathway databases compiled from many different sources (Ge, Jung \& Yao, 2020). We searched for differentially expressed KEGG pathways and GO terms associated with reproduction, including GnRH synthesis, release, and stability of reproductive hormones and metabolic pathways associated to migratory processes. The goal was to identify functional correlates of seasonal divergence in reproductive and migratory timing in free-living birds belonging to closely related populations living in sympatry but diverging in behavior and physiology related to annual timing.

\section{Material and Methods}

\section{Capture and tissue collection-}

We captured adult male migrant and resident dark-eyed juncos ( $\mathrm{n}=5$ each) using mist nets on state road 714 , Giles County Virginia near Mountain Lake Biological Station (MLBS; $\left.37.37^{0} \mathrm{~N}, 80.52^{0} \mathrm{~W}\right)$. Migrants $(J . h$. hyemalis $)$ and residents (J.h. carolinensis ) were readily identified based on the bill color, plumage color, and difference in wing cord (Ketterson \& Nolan, 1976). All birds were caught between 18 and 24 March 2017. A schematic figure shows the sampling site (Fig. 1 a), latitudinal differences in the timing of reproduction in dark-eyed juncos (Fig. 1 b), and a workflow illustrating the steps applied in the proteome study (Fig 1 c, d). We collected the most distal secondary feather of the right wing and claw from each individual at the time of capture for stable hydrogen isotope $\left(\delta^{2} \mathrm{H}\right)$ analysis. We measured indicators of reproduction and migration preparedness, including subcutaneous fat score (FS), cloacal protuberance volume (CPV) and body mass (BM) (Fudickar et al., 2016b; Greives et al., 2016; Singh et al, 2019).

We also collected 50-100 $\mu \mathrm{l}$ of blood by puncturing the wing vein for baseline testosterone hormone measurement. Following blood collection, birds were euthanized using isoflurane for tissue harvesting. Hypothalamus and pituitaries were dissected from the whole brain and flash frozen immediately. The tissues were stored at $-80^{\circ} \mathrm{C}$ freezer until processing. Scientific collecting permits were issued by the Virginia Department of Game and Inland Fisheries (permit \# 052971) and the USFWS (permit \# MB093279). All methods were approved under protocol (\# 15-026-17) by the Indiana University Institutional Animal Care and Use Committee.

\section{(b) Stable hydrogen isotope analyses}

We used stable isotope analysis of hydrogen $\left(\delta^{2} \mathrm{H}\right)$ in feathers and claws to infer breeding and overwintering latitudes, respectively (Hobson, 1999; Rubenstein \& Hobson, 2004; Wunder, 2010; Hobson, Van Wilgenburg, Wassenaar, \& Larson, 2012; Bowen, Liu, Vander Zanden, Zhao, \& Takahashi, 2014). Whole feathers and claws were cleaned using a 2:1 chloroform: methanol solution to remove external oils and contaminants. Prior to analysis, we controlled for the effect of exchangeable hydrogen by forcing isotopic equilibration with a water vapor of known isotopic composition in a flow-through chamber system at $115^{\circ} \mathrm{C}$ (Schimmelmann, 
1991; Sauer, Schimmelmann, Sessions, \& Topalov, 2009). The hydrogen isotopic composition of feathers $\left(\delta^{2} \mathrm{H}_{\mathrm{f}}\right)$ and claws $\left(\delta^{2} \mathrm{H}_{\mathrm{c}}\right)$ was then analyzed using a thermal conversion elemental analyzer coupled with a ThermoFinnigan Delta Plus XP isotope ratio mass spectrometer at the Indiana University Stable Isotope Research Facility. The $\delta^{2} \mathrm{H}$ values are reported in standard per mil notation (Standard Mean Oceanic Water) using two reference materials: USGS77 (polyethylene powder) and hexatriacontane $2\left(\mathrm{C}_{36} \mathrm{n}\right.$-alkane 2 ). Analytical precision was \pm 0.6 We then calculated the isotopic composition of the non-exchangeable hydrogen per sample (Schimmelmann, 1991; Schimmelmann, Lewan, \& Wintsch, 1999).

Based on feather and claw $\delta^{2} \mathrm{H}$ values, we performed Bayesian geographic assignments of individual birds during the breeding and overwintering months, respectively, using the assignR package in $\mathrm{R}$ (Ma \& Bowen, 2019; R Core Team 2019). Growing season and monthly precipitation isoscape rasters from waterisotopes.org (Bowen \& Revenaugh, 2003; Bowen, Wassenaar, \& Hobson, 2005), monthly precipitation amount rasters from CHELSA (Karger et al., 2017a, b), and resident dark-eyed junco isotopic data (Hobson et al., 2012; Becker et al., 2019) were utilized to generate geographic assignment probability maps. Latitudinal estimates were extracted from cells within the top $10 \%$ highest posterior probability using the raster package (Hijmans et al., 2019).

\section{(c) Testosterone EIA}

Plasma samples were thawed on ice and $20 \mu \mathrm{l}$ of plasma from each individual was aliquoted into glass tubes. Hormone was extracted using diethyl-ether mixed by agitating and incubation at room temperature for 20 minutes. After incubation, all tubes were snap frozen and supernatant was immediately transferred to a fresh tube. This procedure was repeated three times to extract the hormone and finally the tube was dried using high pressure nitrogen gas. $250 \mu \mathrm{l}$ of assay buffer was added to each tube and $100 \mu \mathrm{l}$ of extracted hormone was used in duplicate wells to run testosterone assay. Plasma testosterone was measured using a high sensitivity testosterone ELISA kit (Enzo ADI-900-176) as per manufacture's protocol. All samples were run on one assay plate with an intra-assay coefficient variability of $0.6 \% \pm 0.06$ (mean $\pm \mathrm{SE}$ ) and sensitivity of $2.6 \mathrm{pg} / \mathrm{ml}$.

\section{Measurement of protein expression}

\section{Lysate preparation and protein digestion}

Individual tissue samples were ground in a Dounce homogenizer (Kimble, catalog no 885301) in $8 \mathrm{M}$ urea (Catalog no 8648-01, Mallinckrodt) in $100 \mathrm{mM}$ ammonium bicarbonate (Catalog no 3003-10, JT Baker) with 20 passes. Lysed proteomes were then subjected to a low-speed spin $(1400 \mathrm{x} \mathrm{g}, 5 \mathrm{~min})$ to remove debris, and ultracentrifugation $(100,000 \mathrm{x} \mathrm{g}, 45 \mathrm{~min})$ to separate membrane and cytosolic fractions. The supernatant was removed and saved as the soluble proteome, while the pellet was washed and resuspended in cold PBS by sonication or in isotonic resuspension solution (20 mM Hepes, $2 \mathrm{mM} \mathrm{DTT}$ ) by pipetting and saved as the membrane proteome. Total protein concentration for each proteome was determined using a Bio-Rad Dc Protein Assay kit, and proteomes were kept at $-80^{\circ} \mathrm{C}$ until further use. Samples were resuspended and denatured in $8 \mathrm{M}$ urea with $100 \mathrm{mM}$ ammonium bicarbonate, $p \mathrm{H}$ 7.8. Disulfide bonds were reduced by incubation for $45 \mathrm{~min}$ at $57{ }^{\circ} \mathrm{C}$ with a final concentration of $10 \mathrm{mM}$ Tris (2-carboxyethyl) phosphine hydrochloride (Catalog no C4706, Sigma Aldrich). A final concentration of $20 \mathrm{mM}$ iodoacetamide (catalog no. I6125, Sigma Aldrich) was then added to alkylate these side chains and the reaction was allowed to proceed for one hour in the dark at $21{ }^{\circ} \mathrm{C}$. Aliquots of $100 \mu \mathrm{g}$ protein were taken and diluted to $1 \mathrm{M}$ urea using $100 \mathrm{mM}$ ammonium bicarbonate, $p \mathrm{H}$ 7.8. Two $\mu \mathrm{g}$ of trypsin (V5113, Promega) was added and the samples were digested for 14 hours at $37{ }^{\circ} \mathrm{C}$.

\section{Tandem Mass Tag (TMT) labeling and cation exchange-based fractionation of peptides}

The digested lysates were desalted using C18 Omix tips (catalog no A57003100, Agilent) and dried down in $50 \mu \mathrm{g}$ portions. For each of the conditions, $50 \mu \mathrm{g}$ of digested peptides were labeled with the TMT 10plex reagent (catalog no 90113, ThermoFisher). Dried pellets were resuspended in $50 \mu \mathrm{L}$ of $1 \mathrm{X}$ phosphate buffered saline and to each tube, one aliquot of the respective TMT reagent, which was resuspended in 41 
$\mu \mathrm{L}$ of acetonitrile, was added. The reaction was allowed to proceed at $21^{\circ} \mathrm{C}$ for one hour and then quenched via the addition of $8 \mu \mathrm{L}$ of $1 \mathrm{M}$ ammonium bicarbonate. Samples were dried down and then desalted using Omix tips. The individual TMT labeled samples were pooled and fractionated using strong cation exchange chromatography on an AKTA Pure 10 (GE Healthcare) equipped with a Luna $5 \mu \mathrm{m} 100$ angstrom $150 \mathrm{x}$ $2.1 \mathrm{~mm}$ strong cation exchange (SCX) column (catalog no 00F-4398-B0, Phenomenex). Buffer A was $5 \mathrm{mM}$ $\mathrm{KH}_{2} \mathrm{PO}_{4}$ in $30 \%$ acetonitrile (catalog no 34998, Sigma Aldrich), $p$ H 2.7. Buffer B was $350 \mathrm{mM} \mathrm{KCl}$ (catalog no PX1405 EM Science) in buffer A. A $200 \mu \mathrm{L} / \mathrm{min}$ gradient was run from $0 \%$ B to $50 \%$ B over $10 \mathrm{ml}$, then up to $100 \%$ B over $1 \mathrm{ml}$. A total of 12 fractions were collected during the peptide elution portion of the gradient.

\section{Mass spectrometry (MS)}

Individual fractions from the strong cation exchange (SCX) chromatography were desalted using ZipTips (ZTC18S096, EMD Millipore), dried down and resuspended in $0.1 \%$ formic acid (Catalog no 94138, Honeywell). Fractions were analyzed by LC-MS on an Orbitrap Fusion Lumos (ThermoFisher) equipped with an Easy NanoLC1200 HPLC (ThermoFisher). Peptides were separated on a $75 \mu \mathrm{m} \times 15 \mathrm{~cm}$ Acclaim PepMap100 separating column (Thermo Scientific) downstream of a $2 \mathrm{~cm}$ guard column (Thermo Scientific). Buffer A was $0.1 \%$ formic acid in water. Buffer B was $0.1 \%$ formic acid in $80 \%$ acetonitrile. Peptides were separated on a two-hour gradient from $0 \%$ B to $35 \%$ B. Peptides were collisionally fragmented using HCD mode. Precursor ions were measured in the Orbitrap with a resolution of 120,000. Fragment ions were measured in the Orbitrap with a resolution of 50,000. The spray voltage was set at $2.2 \mathrm{kV}$. Orbitrap MS1 spectra (AGC $1 \times 10^{6}$ ) were acquired from 400-1800 m/z followed by data-dependent HCD MS/MS (collision energy $42 \%$, isolation window of $0.7 \mathrm{Da}$ ) for a three second cycle time. Charge state screening was enabled to reject unassigned and singly charged ions. A dynamic exclusion time of 60 seconds was used to discriminate against previously selected ions.

\section{Database search}

The LC-MS/MS data was searched against a junco protein database generated from a recently annotated dark-eyed junco genome. For each of the transcribed regions of the junco genome described as "gene silhouettes," the best scoring match among protein sequences fromGallus gallus, Taeniopygia guttata and Ficedula albicollis was identified using BLASTX program of the BLAST software version 2.9 .0 allowing search against all six reading frames. Each best hit protein sequence was aligned to the corresponding gene silhouette nucleotide sequence using BLAT version 35 (Kent, 2002). The open reading frame (ORF) sequence was selected from the longest hit reported by BLAST. Proteome Discoverer version 2.1.1.21 (ThermoScientific) was used to interpret and quantify the relative amounts from the diagnostic fragment ions. The database search parameters were set as follows: two missed protease cleavage sites were allowed for trypsin digested with 5ppm precursor mass tolerance and $20 \mathrm{ppm}$ for a fragment ion quantification tolerance. Trypsin was set as the protease with up to two missed cleavages allowed. Oxidation of methionine, pyroglutamine on peptide amino termini and protein $\mathrm{N}$-terminal acetylation were set as variable modifications. Carbamidomethylation $(\mathrm{C} ;+57 \mathrm{Da})$ was set as a static modification. TMT 10 plex was set as a constant modification on peptide amino termini and lysine residue side chains. Data were searched using the Sequest HT algorithm and the results were filtered via Percolator with a decoy database false discovery rate (FDR) set to $<1 \%$ as a filter for peptide identification (Spivak, Weston, Bottou, Käll, \& Noble, 2009).

\section{(e) Statistics}

Relative abundance ratios were calculated in Proteome Discoverer and the data were both row and column (i.e., protein and sample) normalized to an average value of 100 . Data are shown as the mean $\pm \mathrm{SE}$. A student $t$ -test was used to find variation between feather $\left(\delta^{2} \mathrm{H}_{\mathrm{f}}\right)$, claw $\left(\delta^{2} \mathrm{H}_{\mathrm{c}}\right)$ hydrogen isotope ratios, and physiological response variables (i.e., CPV, T, FS, and BM) measured in two groups. We initially compared normalized abundances for each protein between residents and migrants using standard two sample $t$-test, followed by multiple correction test based on a sequential goodness of fit (SGoF) metatest (Carvajal- Rodríguez, UñaÁlvarez, \& Rolán-Álvarez, 2009). Because of small sample size, individual protein abundance comparisons 
exhibit large sample variance, and small fold changes. Stringent multiple testing correction methods to calculate false discovery rate (FDR) for multiple repeated $t$-tests are often not suitable for small sample size proteome experiments. In such condition a liberal multiple testing correction methods SGoF metatest can be a valuable approach for multitest adjustment. All statistical analyses were conducted using $\mathrm{R}$ (version 3.2.0) or GraphPad Prism version 6 , and a $\mathrm{p}$ value $<0.05$ was considered significant.

\section{(f) Bioinformatics analysis}

To study the enriched biological function and significant pathways of the differentially expressed proteins, the identified proteins UniProt IDs were used to run Gene Ontology (GO) term analysis. The homology search was performed for all identified sequences against the zebra finch (Taeniopygia guttata) using NCBI BLASTX program (Kent, 2002). The zebra finch Uniprot IDs were assigned for the best hit sequence for GO annotation and enrichment analysis using ShinyGO online software (Ge et al., 2020). The GO enrichment results were presented in three functional categories based on the properties of the identified proteins: biological process (BP), cellular component (CC), and molecular function (MF). In addition, all the differentially expressed proteins were searched against the Kyoto Encyclopedia of Gene and Genomes (KEGG) database to identify the significant KEGG pathways. To further identify significant mechanisms underlying differentially expressed proteins associated with functional clusters of DEPs, GO term enrichment and KEGG pathways analysis was performed by Fisher's exact test. GO terms with FDR values $<0.05$ and KEGG pathways with FDR p values $<0.1$ were identified as significantly enriched.

\section{Results}

\section{Feather and claw hydrogen isotope values}

The feather hydrogen isotope $\left(\delta^{2} \mathrm{H}_{\mathrm{f}}\right)$ values were significantly higher and predicted latitudes were significantly lower in resident than in migrant juncos (Fig. 2 a, b, e, f; S1, S2; Table S1). The two populations exhibited non-intersecting ranges of $\delta^{2} \mathrm{H}_{\mathrm{f}}$ values, suggesting distinct, non-overlapping breeding latitudes (migrants $\delta^{2} \mathrm{H}_{\mathrm{f}}$ range $=-121.07--98.8$ residents $\delta^{2} \mathrm{H}_{\mathrm{f}}$ range $=-60.0--42.9\left(\delta^{2} \mathrm{H}_{\mathrm{c}}\right)$ values did not differ between migrants and residents, suggesting that they overwintered at the same latitude (Fig. 2c, d, g, h; S1, S2; Table S1). Difference in the latitude of breeding and development of immature juncos provide a strong rationale to investigate the difference in the neuroendocrine response between resident and migrant junco populations.

\section{Physiological measures for migratory and reproductive preparedness}

Resident cloacal protuberance volumes and testosterone were both higher than migrants (CPV, $\mathrm{p}=0.0006$; $\mathrm{T}, \mathrm{p}=0.002$; Student $t$-test; Fig. $3 \mathrm{a}$, b; Table S1), confirming that they were at a more advanced stage of reproduction at the time of sampling. There was no difference in body mass between migrants and residents (Fig. 3 c; Table S1), but the fat score was significantly higher in migrants than residents $(\mathrm{p}=0.02$; Student $t$-test; Fig. 3 d; Table S1),

\section{Global proteomics of hypothalamus and pituitary neuroendocrine tissue}

A total of 3038 unique proteins were identified and areas under the curve (AUC) were quantified. Of these quantified proteins, $38.86 \%$ (1059) proteins were inferred from one peptide and $65.14 \%$ (1979) from proteins with two or more than two unique peptides (Table S2). The molecular weights of the identified proteins were in the range of $1.7 \mathrm{kDa}$ to $665.3 \mathrm{kDa}$, and the predicted isoelectric points $(\mathrm{pI})$ were in the range of 12.37 highest and 3.79 lowest respectively. The mass spectrometry proteomics data have been deposited with the Proteome Xchange Consortium via the MassIVE partner repository with the dataset identifier ftp://MSV000085662@massive.ucsd.edu and password: Junco.

\section{Differentially protein expression and gene ontology term enrichment analysis}

We identified 75 proteins that varied significantly between the resident and migrant juncos in early spring. Of these differentially expressed proteins (DEPs), both populations showed equal number of overexpressed proteins (Fig 4a, Table S3). The top 30 significant GO terms were extracted from the DEPs in resident and migrant juncos $(\mathrm{FDR}<0.05)$. The top 5 GO annotations in each, biological process, cellular component, 
and molecular function, are shown in Figure 4b. The most abundant categories in biological process were nuclear-envelope organization, RNA processing, ribonucleoprotein complex biogenesis, negative regulation of cellular catabolic process, posttranscriptional regulation of gene expression, regulation of protein metabolic process, neuropeptide signaling pathway, peptide hormone processing, regulation of GTPase activity, and cell morphogenesis involved in neuron differentiation (FDR $<0.05$; Figure $4 \mathrm{~b}$; Table $\mathrm{S} 4 \mathrm{a}$ ).

The cellular component GO terms showed that DEPs were mainly located in cytoplasm, neuron projection cytoplasm, endomembrane system, vesicle, axon, and neuron projection (FDR $<0.05$; Figure $4 \mathrm{~b}$; Table $\mathrm{S}$ 4b). The most abundant GO terms in the molecular function category were protein binding, mRNA 3-UTR binding, adrenergic receptor binding, unfolded protein binding, GTPase activator activity, enzyme regulator activity, and exopeptidase activity (Figure 4b; Table S 4c). Based on published literature search, DEPs that were also present in significant GO terms associated to reproduction (ITRP3, PURA, RP2, UCHL1, PENK, AGPAT4, GAD2, 7B2, CBE, DUSP1; Fig. 5a, Table S2), migration (SIK3, RSG7, HMGN5, DOCK7, SEPTIN 7, NCK2, STONIN 2, AIF, MCT2; Fig 5b, Table S2), and circadian clock (TARDBP, VIP, SIK3; Fig 5c, Table S2) processes were plotted as boxplot.

\section{KEGG pathways enrichment of DEPs}

KEGG analysis was used to identify the significant functional pathways enriched with differentially expressed proteins. Of the DEPs we obtained 9 significant KEGG pathways (FDR $<0.1$; Table 1 ). These DEPs were mainly classified into oocyte meiosis, nucleotide excision repair, ErbB signaling pathway, gap junction, GnRH signaling pathway, vascular smooth muscle contraction, RNA transport, protein processing in endoplasmic reticulum (FDR $<0.05$ ), and other pathways related to metabolic processes (FDR $<0.1$ ). Among all the DEPs, the GnRH signaling pathway, and the protein processing pathway were most strongly related to the known difference in seasonal reproductive timing in resident and migrant juncos.

\section{Discussion}

We compared early spring proteomic profiles of neuroendocrine tissues (hypothalamus and pituitary gland) derived from two populations of free-living dark-eyed juncos that differ in timing of reproduction and whether or not they migrate. Feathers hydrogen isotope values were significantly higher in resident juncos, indicating a lower breeding latitude than migrants (Fudickar et al., 2016b; Singh et al., 2019). The discrete nonoverlapping feather $\delta^{2} \mathrm{H}_{\mathrm{f}}$ values provide strong evidence that the populations do not have overlapping breeding ranges. The hydrogen isotope values measured in claw tissue that were grown on their wintering location did not differ between two populations, suggesting that both groups overwintered at the capture site (Lymburner, Kelly, Hobson, \& MacDougall-Shackleton, 2016; Kimmitt, Hardman, Stricker, \& Ketterson, 2019). Together, feather and claw $\delta^{2} \mathrm{H}$ data indicate that migrant and resident juncos in the current study were sympatric during winter and originated from different breeding latitudes. Resident juncos (earlier breeding) exhibited larger cloacal protuberances and higher levels of circulating testosterone than migrants; whereas, migrant juncos had greater fat deposits than resident juncos, supporting our hypothesis that the two seasonally sympatric junco subpopulations differ in indices of reproductive and migratory preparedness in early spring, despite exposure to the same environmental cues at their overwintering location.

Prior research on this system using transcriptomics and quantification of specific target genes has shown variation in gene expression in tissues related to the phase lag in the timing of reproduction in migrants as compared to residents, including muscle, blood, and brain (Fudickar et al., 2016a; Bauer et al., 2018; Singh et al., under preparation). But to our knowledge, prior research has not quantified neuroendocrine proteins as a functional correlate for reproductive timing and migratory preparedness.

Results reported here provide a comparative proteome for the neuroendocrine system for birds sampled in the wild in early spring as residents prepare to breed while migrants prepare to migrate. We found a number of proteins thought to play critical roles in GnRH1 transcription, translation, post-translational modification, stability, and synthesis and release in hypothalamic and pituitary gonadotrophs to be more abundant in early recrudescing resident juncos. In contrast, we found increased levels of different proteins involved in cholesterol homeostasis, positive regulation of angiogenesis, oxidative reductive processes, neuron and 
dendrite morphogenesis, and proteins that possibly foster hyperphagia, fat gain and migratory locomotor activity to be more abundant in migrants. These results provide important insight into how differences in neuroendocrine sensitivity to day length give rise to population-level variation in timing in songbirds occupying the same environment while some are preparing to breed, while others are preparing to migrate. To aid in interpretation of the role played by the differentially identified proteins, we turned to the literature in other better-studied taxa, particularly mammals.

\section{Endocrine signaling associated with earlier timing of reproduction in resident juncos-}

The hypothalamus is the top-most locus of the HPG neuroendocrine system where photoperiodic signals are perceived and transformed into an endocrine response that leads to HPG axis activation and gonad recrudescence. In many avian species, an increase in the hypothalamic neuropeptide GnRH1 levels is known to be a key event that stimulates release of luteinizing hormone from pituitary and eventually leads to gonadal stimulation and testosterone synthesis (Cho et al., 1998). Thus, any regulatory process that influences GnRH transcription, translation, proteolytic processing to produce mature hormone, stability of peptide, synthesis and release of hormone could play a critical role in the process of gonad recrudescence. We consider here the potential role of proteins known to be related to GnRH that were found in greater abundance in resident juncos (DUSP1, PURA, CBE, 7B2, GAD2, ITPR3, AGPAT4, PENK, UCHL1, RP2).

The binding of GnRH molecule to the GnRH receptor triggers a cascade of mitogen-activated protein kinase C (MAPK) signaling and dual-specificity phosphatases (DUSP), both immediate early genes (Conn, McArdle, Andrews, \& Huckle, 1987; Stojilkovic, Reinhart, Catt, 1994; Kondoh \& Nishida, 2007). DUSP1 is a dephosphorylating enzyme shown to act in the feedback regulation of phosphorylated MAPK in association with increased GnRH in the gonadotrophs (Zhang, \& Roberson, 2006). DUSP1 has also been observed in luteinizing hormone beta ( $\mathrm{LHb}$ ) subunit gene expression in gonadotrophs (Purwana, Kanasaki, Oride, \& Miyazaki, 2010). A few studies in the mouse neuronal GT1-7 cells suggest that enhanced occupancy of GnRH 1 gene upstream promoter by a transcription factor purine-rich element-binding protein (PURA) downregulated GnRH 1 mRNA levels, suggesting PURA as a repressor of GnRH1 gene transcription (Zhao, Kelm Jr., Fernald, 2010). We note that migratory juncos showed higher level of PURA protein than residents, which could be related to delay in their reproduction.

We found another intracellular second messenger protein ITPR3 to be more abundant in the neuroendocrine tissue of earlier reproducing resident juncos as compared to migrants. ITPR3 is a member of the inositol 1,4,5-triphosphate (IP3) receptor family known to trigger a signaling cascade that facilitates the binding of GnRH to its receptor found on gonadotrophs in the pituitary of huoyan geese (Luan et al., 2017). In contrast this protein is found in lower levels during the laying period in a goose, suggesting that later in the reproductive cycle ITPR2a can also play a role in negative feedback arising from prolonged GnRH or LH secretion (Luan et al., 2017).

Resident juncos had higher abundance of acylglycerophosphate acyltransferase family (AGPAT4) protein, which plays an important role in the synthesis and maintenance of N-methyl-D-asparate (NMDA) and $\alpha$ amino-3-hydroxy-5-methyl-4-isoxazolepropionic acid (AMPA) receptors. NMDA and AMPA receptors are essential for reproduction in mammals (Christian \& Moenter, 2010). Glutamic acid decarboxylase (GAD) was also present in higher abundance in resident juncos. GAD is a rate-limiting enzyme that converts glutamate to GABA, an inhibitory neurotransmitter, and the literature emphasizes an inhibitory role of GABA in GnRH release. Given earlier reproduction by residents in this study, the finding is surprising, but we know that GnRH release is known to result from the interaction of many other neurotransmitters present on the cell membrane (Christian \& Moenter, 2010). Interestingly, we also found higher abundance of a protein, retinitis pigmentosa $2(\mathrm{RP} 2)$ in residents. RP2 is found in the synaptic region of rod and cone photoreceptors and acts as an importer in membrane protein trafficking in mammals (Holopainen et al., 2010). Photoperiod in bird is detected by deep brain photoreceptors (Nakane et al., 2010), so its presence in high abundance in resident junco suggests its role in perceiving and transducing photoperiodic information by hypothalamic deep brain rod photoreceptors. 
Another protein in higher abundance in residents was carboxypeptidase E (CBE). CBE is an endoproteolytic enzyme located in the secretory granules of neuroendocrine cells that play a vital role in peptide hormone and neuropeptide biosynthesis (Fricker, 1988; Cawley et al., 2012; Ji et al., 2017). Elimination of the CPE gene in mice leads to infertility associated with a defect in hypothalamic GnRH 1 proteolytic processing (Wetsel, Liposits, Seidah, \& Collins, 1995; Cawley et al., 2012). Higher expression of CBE protein in residents possibly accelerates the proteolytic cleavage of pro GnRH to synthesize mature GnRH hormone. The posttranslational proteolytic process of transforming inactive neuropeptide hormones to biologically active peptides is achieved partly through the family of prohormone convertases (PCs) (Nillni, 2007).

Similar, to CBE, the neuroendocrine protein 7B2 is also expressed at higher levels in resident juncos. This protein is involved in the activation of an endoprotease prohormone convertase 2 (PC2). Previous studies indicate that the large amount of stored 7B2 protein observed in gonadotroph cells of the mammalian pituitary plays a critical role in hormone regulation (Westphal et al., 1999; Mbikay, Seidah, \& Chrétien, 2001). Finally, ubiquitin C-terminal hydrolase L1 (UCHL1), a deubiquitinating enzyme expressed in the anterior pituitary, was more abundant in residents. In mice, UCHL1 genetic knock out mice (akagad mice) exhibit a significant decrease in gonadotropic, lactotropic cells in the anterior pituitary, suggesting a critical role for this enzyme in the GnRH stability in gonadotrophs, and activation of HPG axis (Xu, Hideshima, Ishii, Yoshikawa, \& Kyuwa, 2014). In addition to proteins associated with GnRH synthesis and release, we also found proenkephalin (PENK) to be more abundant in resident juncos. PENK is an endogenous opioid peptide that has been suggested to play a role in the regulation of negative feedback on luteinizing hormone releasing hormone (LHRH) in domestic fowl (Scanes \& Pierzchala-Koziec, 2018).

Proteins associated with migratory preparation-

Unlike the neuroendocrine system that regulates reproduction, no specific neural center has yet been localized that controls the migratory process. Migratory preparedness is characterized by increased food intake, fat deposition, and locomotion (nighttime restlessness in captivity; aka Zugunruhe, Trivedi et al., 2014; Singh et al., 2015). We found several DEPs that have been studied in the control of food intake and energy balance. Among the most relevant proteins that were more abundant in migrants than residents were monocarboxylate transport protein (MCT2) and apoptosis-inducing factor (AIF). MCT2 is involved in the transport of shortchain monocarboxylates such as pyruvate, ketone bodies, lactate and a-hydroxybutyrate, which play an essential role in energy balance (Elizondo-Vegal, Salgado, \& Gracía-Robles, 2016). Studies of MCT2 protein in the regulation of food intake have located it in both orexigenic and anorexigenic neurons (Cortés-Campos et al. 2013). Specifically, projections from tanycyte specialized ependymal cells found on the lining of third ventricle of the brain communicate directly with MCT2 positive neurons that synthesize and release key neuropeptides such as proopiomelanocortin (POMC), agouti related protein (AgRP), and neuropeptide Y (NPY) that control food intake (Elizondo-Vega et al., 2015). Similarly, AIF protein is known for facilitating utilization of fatty acids for mitochondrial respiration specific to hypothalamic POMC neurons involved in regulation of glucose sensing and energy metabolism (Timper et al., 2018).

Locomotion and navigation are two other important behavioral features that differentiate the migratory junco population from the earlier reproducing resident population. During enhanced locomotor activity, one would expect sustained stimulation of nerve synapses, synaptogenesis, synaptic plasticity, and dendritic spine morphogenesis. We found greater abundance of Stonin 2, NCK2, Septin 7, Dock 7 in migratory juncos, all proteins that have been studied in relation to increased synaptogenesis, synaptic plasticity, dendritic spine morphogenesis, and neurogenesis (Jung et al., 2007; Thévenot et al., 2011; Wang et al., 2018). In addition to proteins that are involved in neuronal plasticity, we also found a member of a high mobility protein family (HMGN5) known to regulate gene expression by modulating chromatin structure (Rochman, Malicet, \& Bustin, 2010). Other proteins present in high abundance in migratory juncos were RSG7 regulators for G protein signaling (RGS) in paraventricular neurons (PVN) (Gold, Ni, Dohlman, \& Nestler et al., 1997), LYRIC known to regulate inflammation, immune response, and angiogenesis (Emdad et al., 2013), and SIK3 known to be associated with regulation of corticotropin releasing hormone transcription in rat hypothalamic neurons (Liu et al., 2012). 


\section{Proteins associated with regulation of circadian system}

Photoperiodic time measurement and seasonal responses involve the circadian system. In mammals, the circadian basis of the seasonal response, the circadian clock pacemaker, has been shown to communicate with the GnRH1 neurons and the feeding center. In contrast, the avian circadian clock consists of a multioscillatory system, and no firm evidence has yet shown direct involvement of circadian clock molecules in day length measurement and photoperiodic response (Singh et al., 2015; Mishra et al., 2017). A few studies have shown expression of clock gene(s), clock controlled genes, accessory clock genes, neuropeptides and neuromodulators that transmit the photic information to a circadian pacemaker located in the hypothalamus and further transduce these inputs to brain areas involved in the regulation of GnRH secretory system, food intake, locomotion, and energy homeostasis (Ward et al., 2009; Rastogi, Kumari, Rani, \& Kumar, 2013). Vasoactive intestinal peptide (VIP) neuropeptide has been implicated in both synchronization of circadian pacemaker cells in mammals (Vosko, Schroeder, Loh, Colwell, 2007) and transduction of the photoperiodic response giving rise to reproduction in birds (Macnamee, Sharp, Lea, Sterling, \& Harvey, 1986; Teruyama \& Beck et al., 2001). Resident juncos showed higher abundance of VIP protein, which may indicate that it has a role GnRH secretion and early gonadal recrudescence. In migrants we found high abundance of salt-inducible kinases 3 (SIK3) and TAR-binding protein 43 (TDP-43). SIK3 is a protein involved in the stability of Period 2 (Per 2) and cryptochromes 1, and 2 (Cry 1,2) respectively (Hirano et al., 2016; Hayasaka et al., 2017). SIK3 and TDP-43 proteins have also been related to energy homeostasis, glucose, cholesterol metabolism, and food intake (Piguet et al., 2011; Hayasaka et al., 2017). These proteins could be directly or indirectly involved in the preparation of pre-migratory physiology.

While proteomics has emerged as a promising tool for clinical study in humans and laboratory raised animals (Klose et al., 2002; Samara et al., 2011), very few studies have addressed eco- physiological questions relevant to seasonal timing and adaptation to changing environment. This scant use of proteome experiments in non-model systems is probably due to challenges in the proteome quantification methods, data analysis, and statistical inference of the data (Kammers, Cole, Tiengwe, \& Ruczinski, 2015). Experimental design for quantitative proteomic studies is not a trivial task, and key factors influencing successful quantitative measurement of proteins includes number of biological replicates, few replicates due to high reagent costs, limited time availability of instruments, technical variation introduced during preparation of samples, digestion, TMT labeling, fractionation, and MS stages of LC-MS/MS analysis (Pascovici, Handler, Wu, \& Haynes, 2016). The TMT-labeling chemistry has the advantage of chemical labeling and sample multiplexing to combine different samples into a single mixture of peptide, which appears to be a suitable approach to overcome any technical variation, batch effect, and increased quantitation of peptides across different samples (O'Connell, Paulo, O'Brien, \& Gygi, 2018).

\section{Conclusion}

Looking to the future, elucidating the cellular and molecular changes that occur between reproductively active and inactive neuroendocrine tissues of resident and migrant birds respectively will require additional approaches, such as localization of proteins or ultrastructure imaging of the hypothalamus and pituitary. The observed differentially expressed proteins involved in calcium ion channel activity, synapse, neuron differentiation, dendrite formation, axon guidance all raise a possibility of seasonal changes in the morphology of nerve terminals in the hypothalamus or in endocrine secretory cells in the pituitary. Cellular localization of specific proteins that play a role in $\mathrm{GnRH}$ synthesis, stability, and release in residents, or that play a role in migratory processes such as increased food intake or synaptogenesis in migrants are needed and will provide added insight into the seasonal regulation of key life history stages in birds. Seasonal neurogenesis in the hypothalamus and other brain areas has been reported in diverse species ranging from zebrafish to hamsters, sheep, and birds (Sousa-Ferreira, de Almeida, \& Cavadas 2014; Pozner, Vistoropsky, Moaraf, Heiblum, \& Barnea, 2018). By considering the potential role of proteins in neurogenesis, synapse formation, and cell proliferation, we found a few key molecules such as PURA, MAP2K1, DPYSLL, PAFAH1B1, STONIN 2, and Hypoxanthine-guanine phosporibosyltransferase that are either directly or indirectly involved in neuron, dendrite morphology and synapse formation. The proteomics analysis of the brain regions controlling the 
neuroendocrine system could be helpful in introducing neuro-proteomics as a new area of study, enabling the improved understanding of the molecular mechanisms and correlates associated with the underlying differential brain response depending on the time of the day, duration of the day length or other environmental factors.

Declaration: Authors have no conflict of interest.

Data Accessibility: The proteomics data are available to the Proteome Xchange Consortium via the MassIVE partner repository with the dataset identifier ftp://MSV000085662@massive.ucsd.edu and password: Junco. Data are available in the Dryad Digital Repository: https://doi.org/10.5061/dryad.f1vhhmgv4

Authors' contribution : DS and EDK conceived the idea. DS and AMF collected field samples. DS carried out the data collection and analysis. TS performed the hydrogen stable isotope analyses and geographic assignments. DS wrote the manuscript with the help of all authors. All authors approved the final draft.

Funding. The funds were provided by Indiana University Grand Challenge Initiative, Prepared for Environmental Change to EDK and TMS, National Science Foundation (IOS- 1856423) and, IU Faculty Research Support Program, (FRSP, account number \# 2224640) to AMF and EDK.

Acknowledgements: We thank Douglas B. Rusch and Ram Podicheti from the Center for Genomics and Bioinformatics (CGB), IU Bloomington for providing junco protein database generated from recently annotated junco genome. We thank Jonathan C. Trinidad for performing proteome sequencing and access to the Biological Mass Spectrometry Laboratory, IU Bloomington. Mountain Lake Biological Station provided access to field sites. We are grateful to Kathryn Evans for help with sample preparation and Peter Sauer at the Indiana University Stable Isotope Research Facility for assistance with isotopic analysis.

Figure 1. Schematic showing geographical distribution of resident (J. h. carolinesis ; red circle, year-round) and migrant (J.h. hyemalis ; orange as breeding area, pale blue as wintering area; based on IUCN, 2019) dark-eyed juncos on the North America map (a). The middle left panel showing the difference in the early breeding resident juncos gonad development than migrants in early spring (b). The middle right panel showing schematic for the isobaric tandem mass tag (TMT) labeling of individual hypothalamic protein samples pooled to run Liquid Chromatography with tandem mass spectrometry (LCMS/MS) (c). The flowchart outline steps of protein sequencing, differentially expressed protein (DEPs) analysis, enriched gene ontology (GO) terms, and significant kyoto encyclopedia of genes and genomes (KEGG) pathway analysis (d).

\section{Hosted file}

image1.emf available at https://authorea.com/users/293676/articles/480438-comparativeproteomics-reveals-molecular-correlates-of-population-level-variation-in-reproductivetiming-in-a-north-american-songbird

Figure 2 . Overlapping geographic assignments for migrant (a, c) and resident (b, d) juncos based on isotopic composition of feathers in yellow $(\mathrm{a}, \mathrm{b})$ and claws in blue $(\mathrm{c}, \mathrm{d})$, representing regions of high probability (top $10 \%$ ) for breeding and overwintering location, respectively. Seasonal ranges for Junco hyemalis (IUCN, 2019) are shown in light gray underneath origination estimates. Hydrogen isotopic values for individual feathers (e) and claws (g) were used to estimate the corresponding median latitudes (f, h) at which those tissues were formed, with asterisks indicating significant differences between resident and migrant juncos.

\section{Hosted file}

image2.emf available at https://authorea.com/users/293676/articles/480438-comparativeproteomics-reveals-molecular-correlates-of-population-level-variation-in-reproductivetiming-in-a-north-american-songbird

Figure 3. Phenotypic and physiological measures: Box plot showing 5\%-95\% intervals of cloacal protuberance volume (a), plasma testosterone (b), body mass (c), and fat score (d) in migrant (hollow box plot) and 
resident (black box plot) juncos. Student's t test was used to determine the significance between migrant and resident response, the alpha was set at 0.05 . An asterisk $\left(^{*}\right)$ indicates a significant difference in parameters compared between migrant and resident juncos.

\section{Hosted file}

image3.emf available at https://authorea.com/users/293676/articles/480438-comparativeproteomics-reveals-molecular-correlates-of-population-level-variation-in-reproductivetiming-in-a-north-american-songbird

Figure 4a. Differential proteome analysis: Heatmap of 75 differentially expressed proteins (DEPs) in migrant and resident neuroendocrine tissue $(\mathrm{FDR}<0.05)$ in which scaled expression values are color coded; greenup-regulated; red - downregulated DEPs (D).

\section{Hosted file}

image4.emf available at https://authorea.com/users/293676/articles/480438-comparativeproteomics-reveals-molecular-correlates-of-population-level-variation-in-reproductivetiming-in-a-north-american-songbird

Figure 4b GO annotation for the differentially expressed proteins in neuroendocrine tissue between migrant and resident juncos. The GO annotation results are displayed under three main categories: biological process, molecular function, and cellular component. The color gradient of the bar chart corresponds to the magnitude of $\mathrm{p}$ value $(\mathrm{FDR}<0.05)$. The dark brown colored bar indicates a low $\mathrm{p}$ value. $\mathrm{Y}$-axis represents the number of differentially expressed proteins in a specific GO term which is labeled on $\mathrm{X}$-axis.

\section{Hosted file}

image5.emf available at https://authorea.com/users/293676/articles/480438-comparativeproteomics-reveals-molecular-correlates-of-population-level-variation-in-reproductivetiming-in-a-north-american-songbird

Figure 5. Boxplot of protein expression values in 5\%-95\% intervals of significantly varied proteins associated to reproduction (a), migration (b), circadian clock (c). X-axis represents the area under the curve as protein expression, Y-axis represents the different proteins compared in resident (black solid bar) and migrant (hollow bar) juncos.

\section{Hosted file}

image6.emf available at https://authorea.com/users/293676/articles/480438-comparativeproteomics-reveals-molecular-correlates-of-population-level-variation-in-reproductivetiming-in-a-north-american-songbird

Table 1. List of significant KEGG pathways associated with functional clusters of differentially expressed proteins (DEPs). KEGG pathways with FDR values $<0.1$ were identified as significantly enriched.

\begin{tabular}{lll}
\hline Functional Category & UniProt ID & Gene ID \\
\hline Oocyte meiosis & H0YUA8, H0ZGH0, H0ZID3 & ITPR3, MAP2I \\
Nucleotide excision repair & H0YUV2, H0ZID3 & Caltractin, RB2 \\
ErbB signaling pathway & H0ZGH0, H0ZHH1 & MAP2K1, NCK \\
Gap junction & H0YUA8, H0ZGH0 & ITPR3, MAP2 \\
GnRH signaling pathway & H0YUA8, H0ZGH0 & ITPR3, MAP2I \\
Vascular smooth muscle contraction & H0YUA8, H0ZGH0 & ITPR3, MAP2 \\
RNA transport & H0ZPR1, H0ZS24 & EIF3E, CLNS1 \\
Protein processing in endoplasmic reticulum & H0ZC03, H0ZID3 & RPN1, RBX1 \\
Metabolic pathways & H0YSC7, H0YXL9, H0Z6P7, H0ZC03, H0ZEQ2, H0ZGD6 & GAD2, Hypoxa \\
\hline
\end{tabular}


Table S1. Results of $t$ - test ( feather, claw stable hydrogen isotope values, breeding latitude, wintering latitude, T, fat score, and body mass) comparing resident and migrant juncos. Results are given as mean \pm SEM.

Table S2. List of total 3038 identified proteins and protein expression as area under the curve for each individual.

Table S3 . List of differentially expressed proteins between resident and migrant juncos. A protein was categorized as differentially expressed with threshold of false-discovery rate (FDR) of $<0.05$.

Table S4 (a-c). List of significant gene ontology (GO) terms were extracted from the differentially expressed proteins in resident and migrant juncos $(\mathrm{FDR}<0.05)$. The list of enriched GO terms was presented in three functional categories based on the properties of the identified proteins: (a) biological process (BP), (b) cellular component (CC), and (c) molecular function (MF).

Figure S1. Left panel: Stacked posterior probability density maps for feather (top) and claw (bottom) geographic assignments for all migrant juncos $(J$. h. hyemalis) individuals $(\mathrm{n}=5)$, with the isotopic composition of each sample shown in the title of the map. Middle panel: From these maps, we retained the cells within the top $10 \%$ highest posterior probability for feathers (in yellow) and claws (in blue) to produce high probability 'threshold' maps, with seasonal range maps shown underneath. Right panel: Histograms represent the range of possible latitudes for each individual based on the threshold maps, with median latitude shown in the histogram title.

Figure S2. Left panel: Stacked posterior probability density maps for feather (top) and claw (bottom) geographic assignments for all resident juncos $(J . h$. carolinensis) individuals $(\mathrm{n}=5)$, with the isotopic composition of each sample shown in the title of the map. Middle panel: From these maps, we retained the cells within the top 10\% highest posterior probability for feathers (in yellow) and claws (in blue) to produce high probability 'threshold' maps, with seasonal range maps shown underneath. Right panel: Histograms represent the range of possible latitudes for each individual based on the threshold maps, with median latitude shown in the histogram title.

\section{References}

Anderson, N. L., Matheson, A. D., \& Steiner, S. (2000). Proteomics: applications in basic and applied biology. Current Opinion in Biotechnology, 11 (4), 408-412. doi: 10.1016/s0958-1669(00)00118-x.

Bairlein, F. (2003). Nutritional strategies in migratory birds. In: Berthold P., Gwinner E., Sonnenschein E. (eds) Avian Migration, pp. 321-332. Springer, Verlag Berlin Heidelberg.

Ball, G. F., \& Balthazart, J. (2003). Birds return every spring like clockwork, but where is the clock? Endocrinology , 144 (9), 3739-3741.

Bauer, C. M., Fudickar, A. M., Anderson-Buckingham, S., Abolins-Abols, M., Atwell, J. W., Ketterson, E. D., \& Grieves, T. J. (2018). Seasonally sympatric but allochronic: differential expression of hypothalamic genes in a songbird during gonadal development. Proceedings of the Royal Society of London B Biological Sciences 285 , 20181735. doi:10.1098/rspb.2018.1735

Becker, D. J., Talbott, K. M., Smiley, T. M., Clark, K. L., Sauer, P. E., \& Ketterson, E. D. (2019). Leukocyte profiles vary with breeding latitude and infection status in a seasonally sympatric songbird.Animal Migration 6 , 28-40. doi:10.1515/ami-2019-0004

Bowen, G. J., \& Revenaugh, J. (2003) Interpolating the isotopic composition of modern meteoric precipitation. Water Resources Research, 39 (10), 1299. doi:10.1029/2003WR002086

Bowen, G. J., Wassenaar, L. I., \& Hobson, K. A. (2005). Global application of stable hydrogen and oxygen isotopes to wildlife forensics. Oecologia 143, 337-348. doi:10.1007/s00442-004-1813-y 
Bowen, G. J., Liu, Z., Vander Zanden, H. B., Zhao, L., \& Takahashi, G. (2014). Geographic assignment with stable isotopes in IsoMAP. Methods in Ecology and Evolution , 5 (3), 201-206.

Berthold, P., Sonnenschein, E. (2003). Avian Migration . Springer, Berlag Berlin Heidelberg.

Brandstätter, R. (2003). Encoding time of day and time of year by the avian circadian system. Journal of Neuroendocrinology ,15 (4), 398-404.

Carvajal-Rodríguez, A., Uña-Álvarez, J., \& Rolán-Álvarez, E. (2009). A new multitest correction (SGoF) that increases its statistical power when increasing the number of tests. BMC Bioinformatics10 , 209.

Cawley, N. X., Wetsel, W. C., Murthy, S. R. K., Park, J. J., Pacak, K., \& Loh, Y.P. (2012). New roles of carboxypeptidase E in endocrine and neural function and cancer. Endocrine Review , 33 (2), 216-253.

Cho, R. N., Hahn, T. P., MacDougall-Shackleton, S., \& Ball, G. F. (1998). Seasonal variation in brain GnRH in free-living breeding and photorefractory House finches (Carpodacus mexicanus). General and Comparative Endocrinology, 109 (2), 244-250.

Christian, C. A., \& Moenter, S. M. (2010). The neurobiology of preovulatory and estradiol-induced gonadotropin-releasing hormone surges. Endocrine Review , 31 (4),544-577

Conn, P. M., McArdle, C. A., Andrews, W. V., \& Huckle, W. R. (1987). The molecular basis of gonadotropinreleasing hormone (GnRH) action in the pituitary gonadotrope. Biology of Reproduction ,36 (1),17-35.

Cortés-Campos, C., Elizondo, R., Carril, C., Martinez, F., Boric, K., Nualart, F., \& Garcia-Robles, M. A. (2013). MCT2 expression and lactate influx in anorexigenic and orexigenic neurons of the arcuate nucleus.PLoS One, 8 (4), e62532.

Dawson, A. (2013). The effect of latitude on photoperiodic control of gonadal maturation, regression and molt in birds. General and Comparative Endocrinology , 190 , 129-133.

Dingle, H. (2006). Animal migration: is there a common migratory syndrome? Journal of Ornithology 147 , $212-220$.

Domon, B., \& Aebersold, R. (2010). Options and considerations when selecting a quantitative proteomics strategy. Nature Biotechnology 28 ，710-721. doi.org/10.1038/nbt.1661

Elizondo-Vega, R., Cortés-Campos, C., Barahona, M. J., Oyarce, K. A., Carril, C. A., \& Gracía-Robles, M. (2015). The role of tanycytes in hypothalamic glucosensing. Journal of Cellular and Molecular Medicine, 19 (7), 1471-1482.

Elizondo-Vega, R., Salgado, M., \& Gracía-Robles, M. (2016). Monocarboxylate Transporters (MCTs) and their Role in Hypothalamic Glucosensing. MedCrave Online Journal of Cell Science \& Report ,3 (4), 00066.

Emdad, L., Das, S. K., Dasgupta, S., Hu, B., Sarkar, D., \& Fisher, P. B. (2013). AEG-1/MTDH/LYRIC: signaling pathways, downstream genes, interacting proteins, and regulation of tumor angiogenesis. Advances in Cancer Research , 120 ,75-111. doi:10.1016/B978-0-12-401676-7.00003-6

Follett, B. K., Kumar, V., \& Juss, T. S. (1992). Circadian nature of the photoperiodic clock in Japanese quail. Journal of Comparativ Physiology A , 171 , 533-540.

Fricker, L. D. (1988). Carboxypeptidase E. Annual Review of Physiology 50, 309-321. doi:10.1146/annurev.ph.50.030188.001521

Fudickar, A. M., Peterson, M. P., Greives, T. J., Atwell, J. W., Bridge, E. S., \& Ketterson, E. D. (2016a). Differential gene expression in seasonal sympatry: mechanisms involved in diverging life histories. Biology Letters , 12 (3), 20160069. doi:10.1098/rsbl.2016.0069

Fudickar, A. M., Greives, T. J., Atwell, J. W., Stricker, C. A., \& Ketterson, E. D. (2016b). Reproductive allochrony in seasonally sympatric populations maintained by differential response to photoperiod: implications 
for population divergence and response to climate change. American Natturalist, 187 (4), 436-446.

Ge, S. X., Jung, D., \& Yao, R. (2020). ShinyGO: a graphical gene-set enrichment tool for animals and plants. Bioinformatics ,36 (8), 2628-2629. doi:10.1093/bioinformatics/btz931

Gold, S. J., Ni, Y. G., Dohlman, H. G., \& Nestler, E. J., (1997). Regulators of G-protein signaling (RGS) proteins: region-specific expression of nine subtypes in rat brain. Journal of Neuroscience, 17 (20), 8024-8037.

Greives, T. J., Fudickar, A. M., Atwell, J. W., Meddle, S. L., \& Ketterson, E. D. (2016). Early spring sex differences in luteinizing hormone response to gonadotropin releasing hormone in co-occurring resident and migrant dark-eyed juncos (Junco hyemalis ). General and Comparative Endocrinology 236 , 17-23.

Gwinner, E., \& Helm, B. (2003). Circannual and circadian contributions to the timing of avian migration. In: Berthold, P., Gwinner, E., \& Sonnenschein, E. (eds) Avian Migration, pp. 81-85. Springer, Verlag Berlin Heidelberg.

Hayasaka, N., Hirano, A., Miyoshi, Y., Tokuda, I. T., Yoshitane, H., Matsuda, J., \& Fukada, Y. (2017). Salt-inducible kinase 3 regulates the mammalian circadian clock by destabilizing PER2 protein. eLife, 6 :e24779.

Helm, B., Ben-Shlomo, R., Sheriff, M. J., Hut, R. A., Foster, R., Barnes, B. M., \& Dominoni, D. M. (2013). Annual rhythms that underlie phenology: Biological time-keeping meets environmental change.Proceedings of the Royal Society of London B Biological Sciences280 , 20130016.

Hijmans, R.J., Etten, Jacob van, Sumner, M., Baston, D., Bevan, A., Bivand, R., ... Wueest, R. (2020). raster: Geographic Data Analysis and Modeling. See https://CRAN.R-project.org/package=raster.

Hirano, A., Nakagawa, T., Yoshitane, H., Oyama, M., Kozuka- Hata, H., Lanjakornsiripan, D., \& Fukada, Y. (2016). USP7 and TDP-43: Pleiotropic Regulation of Cryptochrome Protein Stability Paces the Oscillation of the Mammalian Circadian Clock. PLoS ONE, 11 (4), e0154263. doi:10.1371/journal.pone.0154263

Hobson, K. A. (1999). Tracing origins and migration of wildlife using stable isotopes: a review. Oecologia , 120 (3), 314-326.

Hobson, K. A., Van Wilgenburg, S. L., Wassenaar, L. I., \& Larson, K. (2012). Linking Hydrogen (ס2H) Isotopes in Feathers and Precipitation: Sources of Variance and Consequences for Assignment to Isoscapes.PLoS ONE 7, e35137. (doi:10.1371/journal.pone.0035137)

Holopainen, J. M., Cheng, C. L., Molday, L. L., Johal, G., Coleman, J., Dyka, F., .. Molday, R. S. (2010). Interaction and localization of the retinitis pigmentosa protein RP2 and NSF in retinal photoreceptor cells. Biochemistry , 49 (35), 7439-7447. doi:10.1021/bi1005249.

IUCN. (2019). The IUCN red list of threatened species. Version 2019-3. Retrieved from http://www.iucnredlist.org

Ji, L., Wu, H. T., Qin, X. Y., \& Lan, R. (2017). Dissecting carboxypeptidase E: properties, functions and pathophysiological roles in disease. Endocrine Connect ions, 6 (4),R18-R38. doi:10.1530/EC-17-0020

Johnston, R. A., Paxton, K. L., Moore, F. R., Wayne, R. K., \& Smith, T. B. (2016). Seasonal gene expression in a migratory songbird.Molecular Ecology , 25 (22): 5680-5691. doi: 10.1111/mec.13879.

Jung, N., Wienisch, M., Gu, M., Rand, J. B., Müller, S., Krause, G., .. Haucke, V. (2007). Molecular basis of synaptic vesicle cargo recognition by the endocytic sorting adaptor stonin 2. Journal of Cell Biology, 179 (7), 1497-1510. doi:10.1083/jcb.200708107

Kammers, K., Cole, R. N., Tiengwe, C., \& Ruczinski, I. (2015). Detecting significant changes in protein abundance. EuPA Open Proteomics 7, 11-19. 
Karger, D. N., Conrad, O., Böhner, J., Kawohl, T., Kreft, H., Soria-Auza, R. W., ... Kessler, M. (2017a). Climatologies at high resolution for the earth's land surface areas. Scientific Data4 , 1-20. doi:10.1038/sdata.2017.122

Karger, D. N., Conrad, O., Böhner, J., Kawohl, T., Kreft, H., Soria-Auza, R. W., ... Kessler, M. (2017b) Data from: Climatologies at high resolution for the earth's land surface areas. Scientific Data . See https://doi.org/10.5061/dryad.kd1d4 (accessed on 8 May 2020).

Kent, W. S. (2002). BLAT-the BLAST-like alignment tool. Genome Research 12 , 656-664.

Ketterson, E. D, \& Nolan, V. (1976). Geographic Variation and Its Climatic Correlates in the Sex Ratio of Eastern-Wintering Dark-Eyed Juncos (Junco Hyemalis Hyemalis). Ecology 57 , 679-693. doi:10.2307/1936182

Kimmitt, A. A., Hardman, J. W., Stricker, C. A., \& Ketterson, E. D. (2019). Migratory strategy explains differences in timing of female reproductive development in seasonally sympatric songbirds. Functional Ecology, 33 (9), 1651-1662. (doi:10.1111/1365-2435.13386)

Klose, J., Nock, C., Herrmann, M., Stühler, K., Marcus, K., Blüggel, M., .. Lehrach, H. (2002). Genetic analysis of the mouse brain proteome. Nature Genetics 30 ，385-393. doi.org/10.1038/ng861

Kondoh, K., \& Nishida, E. (2007). Regulation of MAP kinases by MAP kinase phosphatases. Biochimca et Biophysica Acta, 1773 (8) 1227-1237.

Landys, M. M., Piersma, T., Guglielmo, C. G., Jukema, J., Ramenofsky, M., \& Wingfield J. C. (2005). Metabolic profile of long-distance migratory flight and stopover in a shorebird. Proceedings of the Royal Society of London B Biological Sciences 272, 295-302 doi:10.1098/rspb.2004.2952

Liu, Y., Poon, V., Sanchez-Watts, G., Watts, A. G., Takemori, H., \& Aguilera, G. (2012). Salt-inducible kinase is involved in the regulation of corticotropin-releasing hormone transcription in hypothalamic neurons in rats. Endocrinology , 153 (1), 223-233. doi:10.1210/en.2011-1404

Luan, X., Cao, Z., Xing, Z., Liu, M., Gao, M., Meng, B., \& Fan, R. (2017). Comparative proteomic analysis of pituitary glands from Huoyan geese between pre-laying and laying periods using an iTRAQ-based approach. PLoS ONE, 12 (9), e0185253. doi.org/10.1371/journal.pone.0185253

Lymburner, A. H., Kelly, T. R., Hobson, K. A., MacDougall-Shackleton, E. A., \& MacDougall-Shackleton, S. A. (2016). Testosterone, migration distance, and migratory timing in song sparrows Melospiza melodia.Hormones and Behavior 85 , 102-107. doi:10.1016/j.yhbeh.2016.06.013

Ma, C., \& Bowen, G. J. (2019). assignR: Infer Geographic Origin from Isotopic Data version 1.2.0 from CRAN. See https://rdrr.io/cran/assignR/ (accessed on 8 May 2020).

Macnamee, M. C., Sharp, P. J., Lea, R. W., Sterling, R. J., \& Harvey, S. (1986). Evidence that vasoactive intestinal polypeptide is a physiological prolactin-releasing factor in the bantam hen. General and Comparative Endocrinology 62 , 470-478.

Mbikay, M., Seidah, N., \& Chrétien, M. (2001). Neuroendocrine secretory protein 7B2: structure, expression and functions. The Biochemical journal , 357: 329-42.

Mishra, I., Bhardwaj, S. K., Malik, S., \& Kumar, V. (2017). Concurrent hypothalamic gene expression under acute and chronic long days: Implications for initiation and maintenance of photoperiodic response in migratory songbirds. Molecular and Cellular Endocrinology439 , 81-94. doi:10.1016/j.mce.2016.10.023

Nakane, Y., Ikegami, K., Ono, H., Yamamoto, N., Yoshida, S., Hirunagi, K., .. Yoshimura, T. (2010). A mammalian neural tissue opsin (Opsin 5) is a deep brain photoreceptor in birds. Proceedings of the National Academy of Sciences, USA, 107 (34), 15264 15268; doi.org/10.1073/pnas.1006393107 
Nillni ,E. A. (2007). Regulation of prohormone convertases in hypothalamic neurons: implications for prothyrotropin-releasing hormone and proopiomelanocortin. Endocrinology ,148 (9), 4191-4200. doi:10.1210/en.2007-0173

Nolan Jr., V., Ketterson, E. D., Cristol, D. A., Rogers, C. M., Clotfelter, E. D., Titus, R. C., ... Snajdr, E. (2002). Dark-eyed Junco (Junco hyemalis ). In: Poole, A. (Ed.), The Birds of North America Online. Cornell Lab of Ornithology, Ithaca, NY. http://bna.birds.cornell.edu/bna.

O'Connell, J. D., Paulo, J. A., O'Brien, J. J., \& Gygi, S. P. (2018). Proteome-Wide Evaluation of Two Common Protein Quantification Methods. Journal of Proteome Research , 17(5), 1934-1942. doi:10.1021/acs.jproteome.8b00016

Pascovici, D., Handler, D. C., Wu, J. X., \& Haynes, P. A. (2016). Multiple testing corrections in quantitative proteomics: A useful but blunt tool. Proteomics , 16 (18), 2448-2453. doi:10.1002/pmic.201600044

Piersma, T., Perez-Tris, J., Mouritsen, H., Bauchinger, U., \& Bairlein, F. (2005). Is there a "migratory syndrome" common to all migrant birds? Annals of the New York Academy of Sciences 1046 , 282-293.

Piguet, O., Petersén, Å., Yin Ka Lam, B., Gabery, S., Murphy, K., Hodges, J. R., Halliday, G. M. (2011). Eating and hypothalamus changes in behavioral-variant frontotemporal dementia. Annals of Neurology , 69 (2), 312-319. doi:10.1002/ana.22244

Pozner, T., Vistoropsky, Y., Moaraf, S., Heiblum, R., \& Barnea, A. (2018). Questioning Seasonality of Neuronal Plasticity in the Adult Avian Brain. Scientific Reports 8 ， 11289. doi.org/10.1038/s41598-018$29532-1$

Purwana, I. N., Kanasaki, H., Oride, A., \& Miyazaki, K. (2010). Induction of Dual Specificity Phosphatase 1 (DUSP1) by Gonadotropin-Releasing Hormone (GnRH) and the Role for Gonadotropin Subunit Gene Expression in Mouse Pituitary Gonadotroph LbetaT2 Cells1Biology of Reproduction 82 , 352-362.

Ramenofsky, M., Campion A.W., Perez, J. H., Krause, J. S., Nemeth, Z. (2017). Behavioral and physiological traits of migrant and resident white crowned sparrows: a common garden approach. Journal of Experimental Biology 220 , 1330-1340.

Rastogi, A., Kumari, Y., Rani, S., \& Kumar, V. (2013). Neural Correlates of Migration: Activation of Hypothalamic Clock(s) in and out of Migratory State in the Blackheaded Bunting (Emberiza melanocephala ). PLoS ONE 8, e70065.

Rochman, M., Malicet, C., \& Bustin, M. (2010). HMGN5/NSBP1: a new member of the HMGN protein family that affects chromatin structure and function. Biochimica et Biophysica Acta . 1799 (1-2), 86-92. doi:10.1016/j.bbagrm.2009.09.012

Rubenstein, D. R., \& Hobson, K. A. (2004). From birds to butterflies: animal movement patterns and stable isotopes. Trends in ecology \& evolution, 19 (5), 256-263.

Samara, A., Vougas, K., Papadopoulou, A., Anastasiadou, E., Baloyanni, N., Paronis, E., ... Tsangaris, G. T. (2011). Proteomics reveal rat hippocampal lateral asymmetry. Hippocampus, 21 (1), 108-119. doi:10.1002/hipo.20727

Sauer, P. E., Schimmelmann, A., Sessions, A. L., \& Topalov. K. (2009). Simplified batch equilibration for $\mathrm{D} / \mathrm{H}$ determination of non-exchangeable hydrogen in solid organic material. Rapid Communications in Mass Spectrometry 23 , 949-956. (doi:10.1002/rcm.3954)

Sousa-Ferreira, L., de Almeida, L. P., \& Cavadas, C. (2014). Role of hypothalamic neurogenesis in feeding regulation. Trends in Endocrinology and Metabolism 25 , 80-88.

Scanes, C. G., \& Pierzchala-Koziec, K. (2018). Perspectives on Endogenous Opioids in Birds.

Frontiers in Physiology 9 ,1842. doi: 10.3389/fphys.2018.01842 
Singh, D., Fudickar, A. M., Smiley, T. M., \& Ketterson, E. D. (2020). Comparative proteomics reveals molecular correlates of population-level variation in reproductive timing in a North American songbird, Dryad, Dataset, https://doi.org/10.5061/dryad.f1vhhmgv4

Singh, D., Reed, S. M., Kimmitt, A. A., Alford, K. A., \& Ketterson, E. D. (2019). Breeding at higher latitude as measured by stable isotope is associated with higher photoperiod threshold and delayed reproductive development in a songbird. bioRxiv (doi:10.1101/789008)

Singh, D., Swarup, V., Le, H., \& Kumar, V. (2018). Transcriptional Signatures in Liver Reveal Metabolic Adaptations to Seasons in Migratory Blackheaded Buntings. Frontiers in Physiology 9 , 1568. doi: 10.3389/fphys.2018.01568

Singh, D., Trivedi, A. K., Rani, S., \& Kumar, V. (2015). Circadian timing in central and peripheral tissues in a migratory songbird: dependence on annual life-history states. The FASEB Journal,29 (10), 4248-4255.

Schimmelmann, A. (1991). Determination of the concentration and stable isotopic composition of nonexchangeable hydrogen in organic matter.Analytical Chemistry , 63 (21), 2456-2459

Schimmelmann, A., Lewan, M. D., \& Wintsch, R. P. (1999). D/H isotope ratios of kerogen, bitumen, oil, and water in hydrous pyrolysis of source rocks containing kerogen types I, II, IIS, and III. Geochimica et Cosmochimica Acta , 63 (22), 3751-3766.

Spivak, M., Weston, J., Bottou, L., Käll, L., \& Noble, W. S. (2009). Improvements to the Percolator Algorithm for Peptide Identification from Shotgun Proteomics Data Sets. Journal of Proteome Research 8 , 3737-3745. doi: 10.1021/pr801109k.

Stojilkovic, S. S., Reinhart, J., \& Catt, K. J. (1994). Gonadotropin-releasing hormone receptors: structure and signal transduction pathways. Endocrine Reviews, 15 (4), 462-499.

Teruyama, R., \& Beck, M. M. (2001). Double immunocytochemistry of vasoactive intestinal peptide and cGnRH-I in male quail: photoperiodic effects. Cell Tissue Research 303 , 403-414.

Thévenot, E., Moreau, A. W., Rousseau, V., Combeau, G., Domenichini, F., Jacquet, C. .. Barnier, JeanVianney. (2011). p21-Activated kinase 3 (PAK3) protein regulates synaptic transmission through its interaction with the Nck2/Grb4 protein adaptor. Journal of Biological Chemistry , 286 (46), 40044-40059. doi:10.1074/jbc.M111.262246

Timper, K., Paeger, L., Sánchez-Lasheras, C., Varela, L., Jais, A., Nolte, H., ... Brüning, J.C. (2018). Mild Impairment of Mitochondrial OXPHOS Promotes Fatty Acid Utilization in POMC Neurons and Improves Glucose Homeostasis in Obesity. Cell reports,25 (2), 383-397.

Trivedi, A. K., Kumar, J., Rani, S., \& Kumar, V. (2014). Annual Life History-Dependent Gene Expression in the Hypothalamus and Liver of a Migratory Songbird Insights into the Molecular Regulation of Seasonal Metabolism. Journal of biological rhythms , 29 (5), 332-45. doi: 10.1177/0748730414549766

Vosko, A.M., Schroeder, A., Loh, D. H., \& Colwell, C. S. (2007). Vasoactive Intestinal Peptide and the Mammalian Circadian System. General and Comparative Endocrinology 152 , 165-175.

Wang, X., Fei, F., Qu, J., Li, C., Li, Y., Zhang, S. (2018). The role of septin 7 in physiology and pathological disease: A systematic review of current status. Journal of Cellular Molecular Medicine,22 (7), 3298-3307. https://doi.org/10.1111/jcmm.13623

Ward, D. R., Dear, F. M., Ward, I. A., Anderson, S., Spergel, D. J., Smith. P. A., Ebling, F. J. P. (2009). Innervation of Gonadotropin-Releasing Hormone Neurons by Peptidergic Neurons Conveying Circadian or Energy Balance Information in the Mouse. PLoS ONE 4, e5322.

Westphal, C. H., Muller, L., Zhou, A., Zhu, X., Bonner-Weir, S., Schambelan, M., .. Leder, P. (1999). The neuroendocrine protein 7B2 is required for peptide hormone processing in vivo and provides a novel mechanism for pituitary Cushing's disease. Cell, 96 (5), 689-700. 
Wetsel, W. C., Liposits, Z., Seidah, N. G., \& Collins, S. (1995). Expression of candidate proGnRH processing enzymes in rat hypothalamus and an immortalized hypothalamic neuronal cell line.Neuroendocrinology, 62 (2), 166-177

Wunder, M. B. (2010). Using isoscapes to model probability surfaces for determining geographic origins. In: West, J., Bowen, G., Dawson, T., \& Tu, K. (eds) Isoscapes (pp. 251-270).

Springer, Dordrecht. doi.org/10.1007/978-90-481-3354-3_12

Xu, Y., Hideshima, M., Ishii, Y., Yoshikawa, Y., \& Kyuwa, S. (2014). Ubiquitin C-Terminal Hydrolase L1 Is Expressed in Mouse Pituitary Gonadotropes In Vivo and Gonadotrope Cell Lines In Vitro.Experimental Animals , 63 (2), 247-256.

Yasuo, S., Watanabe, M., Okabayashi, N., Ebihara, S., Yoshimura, T. (2003). Circadian clock genes and photoperiodism: Comprehensive analysis of clock gene expression in the mediobasal hypothalamus, the Suprachiasmatic nucleus, and the pineal gland of Japanese quail under various light schedules. Endocrinology , 144 (9), 3742-3748.

Zhang, T., \& Roberson, M. S. (2006). Role of MAP kinase phosphatases in GnRH dependent activation of MAP kinases. Journal of Molecular Endocrinology , 36 (1), 41-50.

Zhao, S., Kelm Jr., R. J., \& Fernald, R. D. (2010). Regulation of gonadotropin-releasing hormone-1 gene transcription by members of the purine-rich element-binding protein family. American Journal of PhysiologyEndocrinology and Metabolism, 298 (3), E524-E533. 10.1152/ajpendo.00597.2009 